\title{
The non-human reservoirs of Ross River virus: a systematic review of the evidence
}

\author{
Eloise B. Stephenson ${ }^{1 *}$, Alison J. Peel ${ }^{1}$, Simon A. Reid ${ }^{2}$, Cassie C. Jansen ${ }^{3,4}$ and Hamish McCallum ${ }^{1}$
}

\begin{abstract}
Understanding the non-human reservoirs of zoonotic pathogens is critical for effective disease control, but identifying the relative contributions of the various reservoirs of multi-host pathogens is challenging. For Ross River virus (RRV), knowledge of the transmission dynamics, in particular the role of non-human species, is important. In Australia, RRV accounts for the highest number of human mosquito-borne virus infections. The long held dogma that marsupials are better reservoirs than placental mammals, which are better reservoirs than birds, deserves critical review. We present a review of 50 years of evidence on non-human reservoirs of RRV, which includes experimental infection studies, virus isolation studies and serosurveys. We find that whilst marsupials are competent reservoirs of RRV, there is potential for placental mammals and birds to contribute to transmission dynamics. However, the role of these animals as reservoirs of RRV remains unclear due to fragmented evidence and sampling bias. Future investigations of RRV reservoirs should focus on quantifying complex transmission dynamics across environments.
\end{abstract}

Keywords: Amplifier, Experimental infection, Serology, Virus isolation, Host, Vector-borne disease, Arbovirus

\section{Background}

\section{Vertebrate reservoir hosts}

Globally, most pathogens of medical and veterinary importance can infect multiple host species [1]. Indeed, an estimated $60-75 \%$ of emerging infectious diseases are multi-host zoonoses [2]. Zoonotic arboviruses, such as Rift Valley fever virus, West Nile virus, and Japanese encephalitis virus, have complex transmission cycles that include multiple host and vector species in maintenance and spillover [2-4]. Identifying optimal approaches to mitigate spillover of multi-host pathogens requires an understanding of how the transmission cycles of zoonotic viruses and non-human hosts contribute to spatiotemporal changes in the patterns of human disease $[1,5,6]$. The challenge of understanding the complex population biology of multi-host pathogens comes not only from identifying potential reservoir host species, but in disentangling which species contribute most to transmission and pathogen pressure, and whether any species are crucial to persistence within the reservoir community $[7,8]$.

The definition of a "reservoir" in infectious disease epidemiology is not straightforward [7]. This is especially the case for arboviruses, where complex and novel

\footnotetext{
* Correspondence: eloise.stephenson@griffithuni.edu.au

${ }^{1}$ Environmental Futures Research Institute, Griffith University, Brisbane,

Queensland 4111, Australia

Full list of author information is available at the end of the article
}

transmission dynamics among arboviruses has resulted in multiple definitions for the key term "reservoir" [9]. Given the diversity of virus-vector-vertebrate host interactions, there is unlikely to be a single definition suitable for all systems or for all applications [9]. Here, we are concerned with identifying which vertebrate hosts contribute most to the pathogen pressure on humans (via infected vectors). We therefore adopt the notion that an arbovirus "reservoir" is a vertebrate host species which, if present in sufficient abundance, will contribute to the pathogen pressure on humans. This will require that it has frequent contact with vector populations, is attractive to a vector as a blood meal source, is susceptible to infection, and can produce sufficient viraemia to infect another vector [9-11]. Kuno and Chang [3] identified three commonly used criteria for classifying vertebrate reservoirs of arboviruses: (i) virus isolation from suspected animals; (ii) relatively high antibody prevalence in the animals captured in the field; and (iii) demonstration of viraemia (of high virus titre and duration) in the suspected animals typically obtained under lab conditions. Methods commonly adopted to address these criteria include virus isolation, serosurveys and experimental infection studies, respectively.

\section{Ross River virus}

Ross River virus (RRV) is a zoonotic alphavirus and human infection is nationally notifiable in Australia. It 
is responsible for the greatest number of mosquitoborne infections in humans across every state and territory of Australia [12]. On average there are 4800 cases of RRV notified per year Australia-wide, with the majority from Queensland [12]. There are occasional large outbreaks of RRV involving a significantly higher number of human cases. In 2015, there were 9800 notifications of RRV - almost double the national average, 6192 of which were reported from Queensland. In 2017, an outbreak occurred in Victoria, with some 1200 notifications reported in January and February alone, exceeding the state counts for the previous four years combined [12].

Ross River Virus is not usually fatal [13]. However, patients with disease caused by RRV infection present with symptoms that include polyarthritis, myalgia, and fever and chronic joint pain which may last several weeks and, in some cases, months [14-16]. The economic costs of illness were estimated to be $\mathrm{A} \$ 1070$ per case in 2002, averaging more than $\mathrm{A} \$ 5$ million each year [17]. This is likely a conservative estimate of RRV cost as it does not include broader implications of infection, such as the inability for an individual to work or care for children [13]. Presently, there is no treatment or commercially available vaccine for RRV and the best means to reduce the risk of infection is through mosquito management and avoidance of mosquito bites [14, 18].

More than 40 species of mosquitoes have yielded isolates of RRV (summarised in [19]), although many are likely to only have a minor role in transmission. Species most commonly associated with transmission include saltmarsh mosquitoes Aedes camptorhychus, presenting in southern Australia and is replaced by Ae. vigilax north of its range, and the freshwater mosquito (Culex annulirostris) that is present throughout Australia, excluding Tasmania [14].

A definitive description of the host-vector relationships in the transmission cycle of RRV is currently not available. Non-human reservoirs of RRV are thought to play a significant role in RRV endemicity [20-22]. While several authors have suggested that human-mosquito-human transmission of RRV may occur during epidemics [23-25], such transmission is not believed to be sufficient to account for the total number of reported cases each year in Australia [19], nor to be responsible for the long-term persistence of RRV.

Marsupials are generally considered better reservoirs of RRV than placental mammals, which in turn are better reservoirs than birds $[13,19,26,27]$. This hypothesis first appeared in the literature in 1971 following epidemiological studies in northern Queensland where high rates of RRV seropositivity were detected in macropods (kangaroos and wallabies) [28]. However, the hypothesis deserves critical re-evaluation because there is evidence that RRV circulates in countries in the Pacific, where marsupials are absent [29-31].

This review aims to: (i) critically review the evidence supporting the hypothesis 'marsupials are better reservoirs of RRV than placental mammals, which in turn are better reservoirs than birds'; (ii) characterise the limitations of that evidence; and (iii) identify research gaps with regards to RRV transmission cycles.

\section{Methods}

We systematically identified original research papers on RRV reservoir as follows. First, we searched electronic databases (Web of Science, ProQuest, Science Direct, PubMed and Google Scholar) for articles published between 1950 and May 2016 using combinations (Additional file 1: Table S1) of the following keywords: 'Ross River virus,' 'Ross River fever,' 'endemic polyarthritis,' 'host,' 'reservoir,' 'wild",' 'captive,' population,' 'serolog*,' 'serosurvey*', 'antibod"', 'virus', 'viral', 'viraemia', 'viremia, 'PCR', 'patholog", 'serum,' 'RNA,' 'vector"'. The asterisk (") operator was used as a wildcard to search for all the possible variations of keywords. We then manually searched bibliographies for additional references. Review papers, studies involving only humans, and studies not reporting original data were excluded. A flow chart showing the article selection process is presented in Additional file 2: Figure S1. A list of the publications included is provided in Additional file 1: Table S2. One person (EBS) was responsible for determining if a paper was included and extracting data. By following the inclusion and exclusion criteria there were no discrepancies for selecting papers.

For each article, we recorded the following information: year of publication, location of study, type of study (experimental infection, serosurvey, virus isolation/detection), method (e.g. for experimental infection studies: the dose, infection technique, strain of RRV used and post infection analysis), species investigated, sample size and results. Species examined in each study were assigned to a species group (marsupial, placental mammal, bird) for interpretation.

\section{Statistical analysis}

A meta-analysis of results across experimental infection studies was not possible as methods of infection and viral detection were highly variable. Instead, we conducted two one-way analysis of variance (ANOVA) for the one experimental infection study that assessed the greatest number of species $(n=10$ species, [27]) to test the hypothesis that the duration of viraemia and peak viral titre differs between species groups (marsupial, placental mammal and bird).

For serosurveys, the seroprevalence range was calculated for each species group (marsupial, placental mammal or bird), and plotted as a boxplot. An ANOVA was used 
to test for differences in seroprevalence between species groups across different studies.

\section{Results}

We identified a total of 38 research papers that met our criteria. Of these studies, seven described experimental infections, five described virus isolation and 29 utilised serosurveys (Table 1) (three studies used multiple methods, Additional file 1: Table S2). All experimental infection studies were undertaken in Queensland. Virus isolation studies were undertaken in Queensland and Victoria. We identified a single article that performed molecular identification of virus from horses [32], but this was excluded from the analysis as the paper was methodological, describing the novel test method. Serosurveys were performed in every state in Australia and the Northern Territory, as well as other countries including Fiji $(n=1)$, New Guinea $(n=1)$ and New Zealand $(n=2)$ (Table 1$)$. The earliest studies of RRV reservoirs included serosurveys in 1966 and virus isolation in 1968.

\section{Experimental infection studies}

The seven experimental infection studies included infection of 18 vertebrate species with RRV (summarised in Table 2). At least two strains of RRV were used: the prototype T48, isolated from a human Townsville in 1959 [13], and B94/20, isolated from a human during an epidemic in Queensland in 1994 [33]. Two studies did not state which strain was used $[27,34]$. The most common route of infection was via infected mosquito $(n=5)$, although subcutaneous $(n=2)$ and intravenous $(n=1)$ routes were also used. All studies assessed the titre of viraemia in blood, but methods and metrics differed. Four of the seven studies subsequently exposed infected animals to susceptible vectors to determine infectiousness of potential reservoirs. Across all studies, the median sample size was 9 individuals, Kay et al. [27] using the largest sample size of 20 chickens (Gallus gallus domesticus). More than half ( 4 of 7 ) of the experimental infection studies undertaken for RRV simultaneously co-infected the same animal with other viruses in addition to RRV, including Barmah Forest virus, Murray Valley encephalitis or Sindbis virus [27, 35-37].

Comparison of viral titres across experimental infection studies is hampered by different measures of viraemia.
Within each study there was substantial variability in the viraemic response reported for different species of animal within each species group and study (i.e. marsupials, placental mammals and birds; Table 3). Whitehead [37] reported the highest peak titres in Antichinus spp. of $8 \mathrm{LD}_{50}$ lasting 144 hours, in contrast to $4.75 \mathrm{LD}_{50}$, lasting 48 hours in rabbits (Oryctolagus cuniculus). Kay et al. [27] reported the highest viremia in horses (Equus caballus) at 6.3 SMIC, compared to black ducks (Anas rubripes) developing a peak titre of 1.8 SMIC. Pigeons (Columba livia domestica), cats (Felis catus) and dogs (Canis lupus familiaris) were the only animals that did not develop a detectable viraemia.

Statistical analysis of the results from Kay et al. [27], the experimental infection study with the greatest number of species $(n=10)$ and largest number of individuals tested $(n=92)$, showed that although viraemia in grey kangaroos (Macropus giganteus) attained moderately high levels and lasted the longest duration (Fig. 1), there was no significant difference (between species groups (marsupial ( $n=11$ individuals, 2 species), placental mammals ( $n=45$ individuals, 5 species) and birds $(n=35$ individuals, 3 species) for both duration of viraemia $\left(F_{(2,9)}=2.312, P=0.169\right)$ and peak titre level $\left(F_{(2,9)}=\right.$ 3.177, $P=0.104)$.

For horses (Equus caballus) and little corellas (Cacatua sanguinea), Kay et al. [27] also used susceptible $C x$ annulirostris vectors to feed on infected hosts to determine the percentage of mosquitoes that became infected with RRV. Despite low titre and short duration viraemias (2.3 SMIC, 50 hours; Fig. 1), little corellas infected 14\% of an unknown number of recipient vectors. Horses developed the highest titre viraemeia (6.3SMIC), of one of the longest durations (112 hours), and infected a comparable $11 \%$ of recipient vectors.

\section{Virus isolation studies}

Isolation of RRV from non-human vertebrate species has been reported in 20 instances in published studies. The majority $(n=15)$ of isolates were recovered from horses (Equus caballus), whilst two isolates were recovered from agile wallabies (Macropus agilis) and three isolates came from birds (Table 4). Virus was isolated from the heart tissue of birds [38] and from serum of horses and wallabies [28, 39]. Virus isolation was achieved using

Table 1 Summary of study types included in the literature review of Ross River virus reservoir studies comprising the number of studies of each type, location and dates of publications

\begin{tabular}{llll}
\hline Study type & Total no. of studies & Location of studies & Date range of studies \\
\hline Experimental infection & 7 & Queensland & $1969-2001$ \\
Virus isolation & 5 & Queensland, Victoria & $1968-2003$ \\
Serosurvey & 29 & Queensland, New South Wales, Western Australia, Victoria, South Australia, & $1966-2015$ \\
& & Northern Territory, Tasmania, New Guinea, Fiji, New Zealand & \\
\hline
\end{tabular}




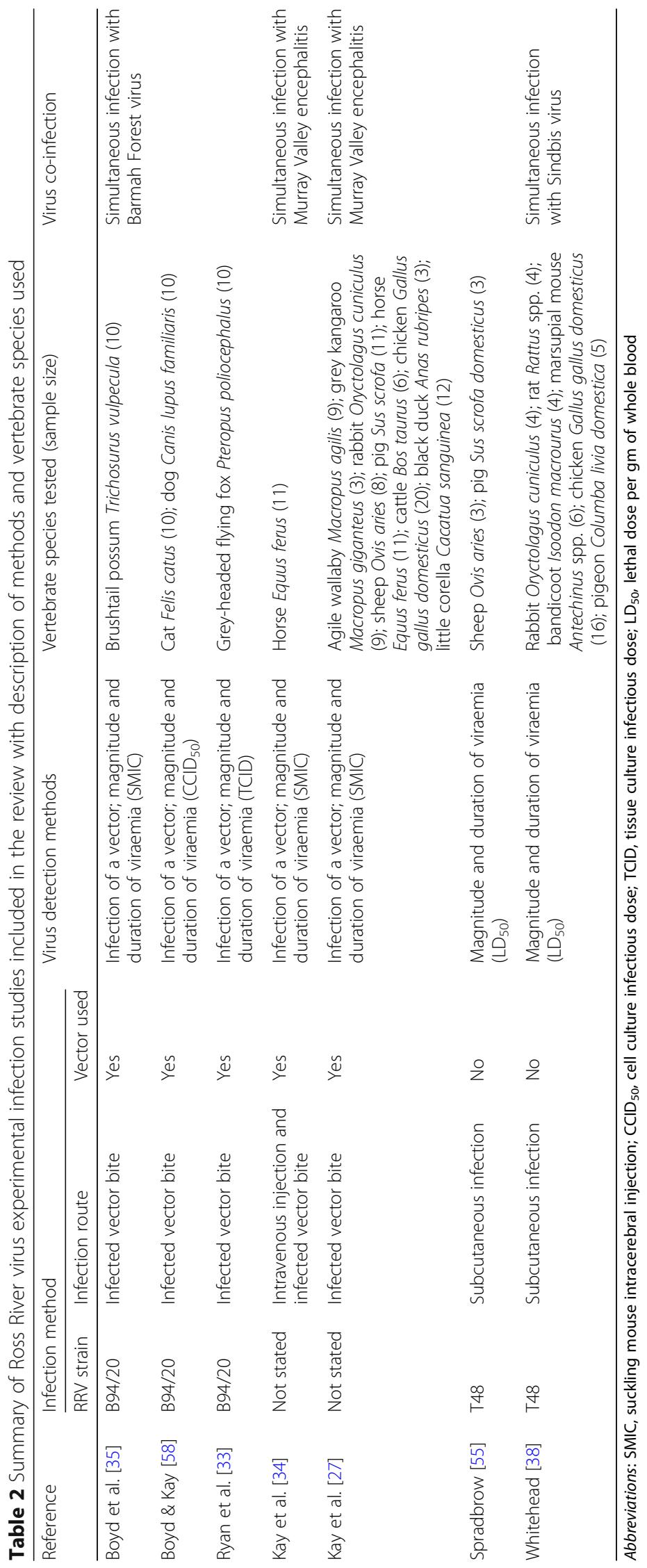




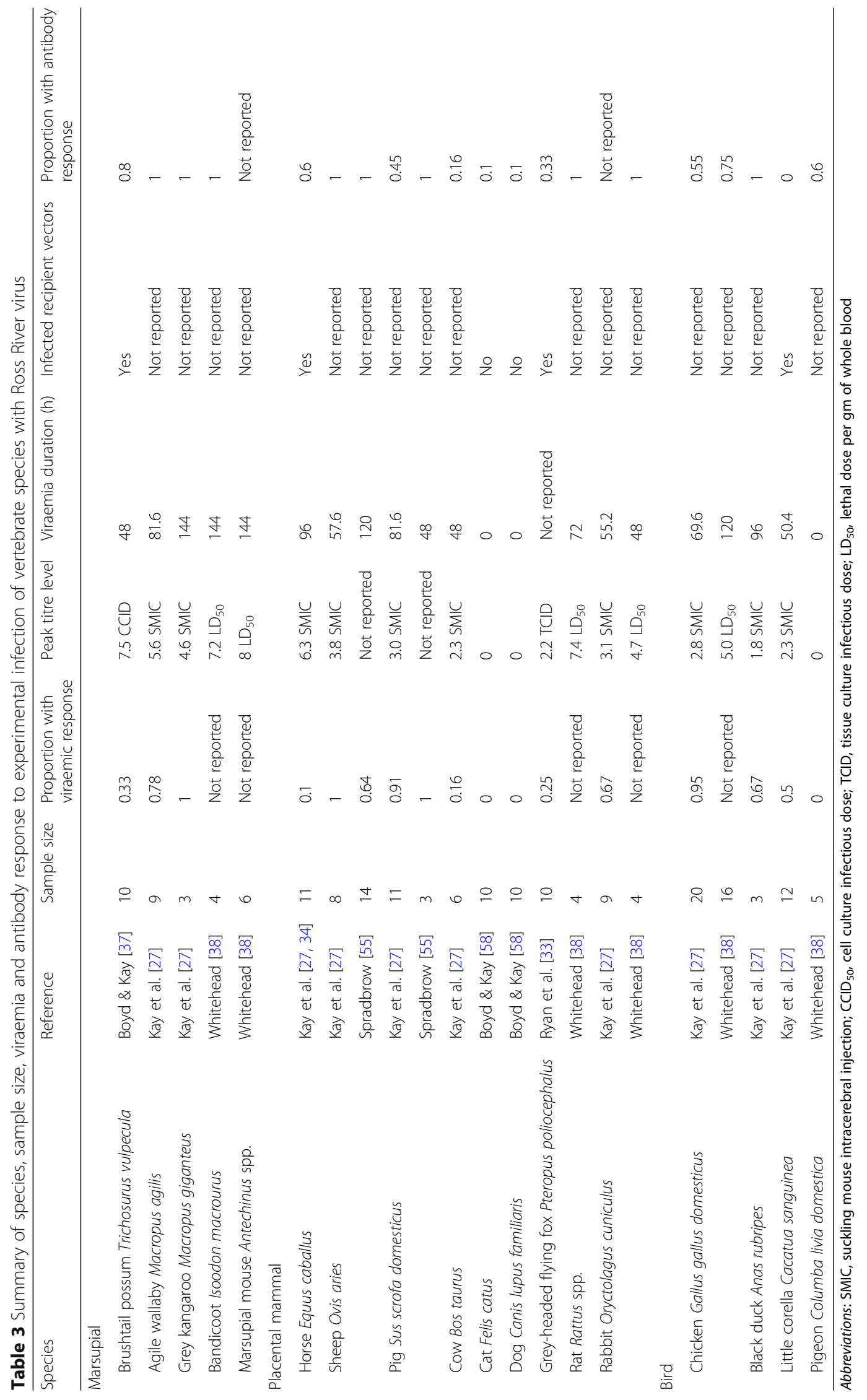






Fig. 1 Mean peak titre and duration of viraemia measured in different animals experimentally infected with Ross River virus, data extracted from Kay et al. [27]. Squares represent marsupials, circles represent mammals and triangles represent birds. Species in order of number: 1, Cow; 2, Little corella; 3, Rabbit; 4, Sheep; 5, Chicken; 6, Pig; 7, Black duck; 8, Agile wallaby; 9, Horse; 10, Grey kangaroo

intracerebral inoculation into infant mice $[28,38]$ or incubation of tissue culture plates with serum followed by identification with antiserum raised in rabbits [40].

\section{Serosurvey studies}

We identified a total of 30 serosurveys studies (Additional file 1: Table S2) that tested more than 17,000 serum samples from 77 host species. The majority of these studies were undertaken in Australia, with a small number in New Zealand, Fiji and Papua New Guinea (Table 1). Serosurveys for RRV in non-human species have spanned almost 50 years and, as such, the methods within these studies vary substantially. Studies were grouped by decade of publication to accommodate the different serological methods and species groups tested (Fig. 2). Earlier studies favoured haemoglobin inhibition. This technique has now largely been superseded in favour of assays with better sensitivity and specificity. Virus neutralisation, either through Plaque Reduction Neutralisation (PRNT) (the gold standard) or serum microneutralisation are highly specific [41] and have been used throughout the decades. These methods are generally considered more labour intensive, require trained personnel and a minimum of five days to perform. More recent serosurveys have used enzyme linked immunosorbent assay (ELISA) which can be purchased in commercial kits and are more commonly used in human diagnostic labs (Fig. 2a). In the first decade (1966-1975) of seroprevalence studies, $80 \%$ of all species sampled were birds (Fig. $2 \mathrm{~b}$ ). In the following decade (1976-1985) more than $82 \%$ of serosurveys were performed on placental mammal species. In the subsequent two decades (1986-2005) marsupial species were sampled most frequently (between $50-60 \%$ of serosurveys), followed by placental mammals (between $32-40 \%$ of serosurveys) and birds (between $0-17 \%$ of serosurveys).

Figure 3 shows the mean seropositivity in each of the three species groups. Half of all species sampled were marsupials ( $n=39$ species), followed by placental mammals $(n=27$ species $)$ and birds $(n=13$ species $)$.

Table 4 The number, study and study sample size for isolates of Ross River virus collected from non-human vertebrates

\begin{tabular}{|c|c|c|c|}
\hline Species & Reference & Sample size & Number of RRV isolations \\
\hline \multicolumn{4}{|l|}{ Marsupial } \\
\hline Agile wallaby Macropus agilis & Doherty et al. [28] & 17 & 2 \\
\hline \multicolumn{4}{|l|}{ Mammal } \\
\hline \multirow[t]{3}{*}{ Horse Equus callabus } & Azuolas et al. [40] & 750 & 13 \\
\hline & Pascoe et al. [39] & 8 & 1 \\
\hline & Campbell et al. [76] & Not reported & 1 \\
\hline \multicolumn{4}{|l|}{ Bird } \\
\hline Magpie lark Grallina cyanoleuca & Whitehead et al. [38] & 775 (104 species) & 1 \\
\hline Flycatcher Myiagra rubecula & & & 1 \\
\hline Masked finch Poephila personata & & & 1 \\
\hline
\end{tabular}




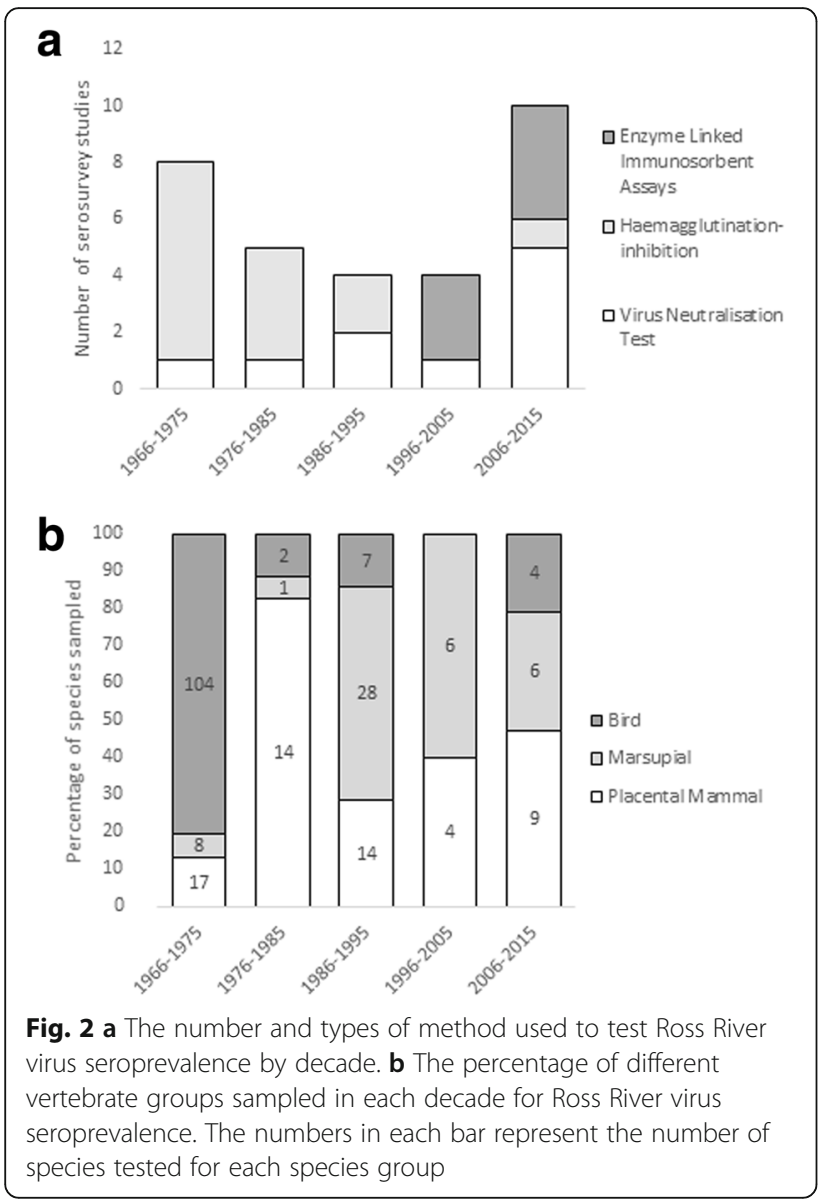

Placental mammals comprised the largest number of sera $(n=10,126)$, more than double that of marsupial sera $(n=4304)$ and quadruple that of bird sera $(n=$ 2621). Within placental mammals, cattle have been sampled most frequently ( $28.9 \%$ of samples), closely followed by horses ( $28.8 \%$ of samples). For marsupials, $46 \%$ of serosurveys were from one study with a focus on western grey kangaroos, Macropus fuliginosus [42]. Within birds, chickens were the most sampled species, contributing $38 \%$ of all samples in this species group.

Overall, there was a significant difference in seroprevalence between species groups $\left(F_{(2,76)}=7.091, P=\right.$ 0.001 ). Across studies, the median seroprevalence in marsupials was greater when compared with placental mammals and birds (44\%, $16 \%$ and $0 \%$, respectively; Fig. $3)$. The interquartile range of seroprevalence was greatest in the marsupial group (5-75\%) and smallest in the bird group (0-6\%) (Fig. 3). Outliers in the bird seroprevalence results included black ducks (Anas superciliosa, 2 of 3 positive) and little corellas (Cacatua sanguinea, 6 of 12 positive). For placental mammals, the highest seroprevalence was observed in red foxes (Vulpes vulpes, 3 of 4 positive) followed by rabbits

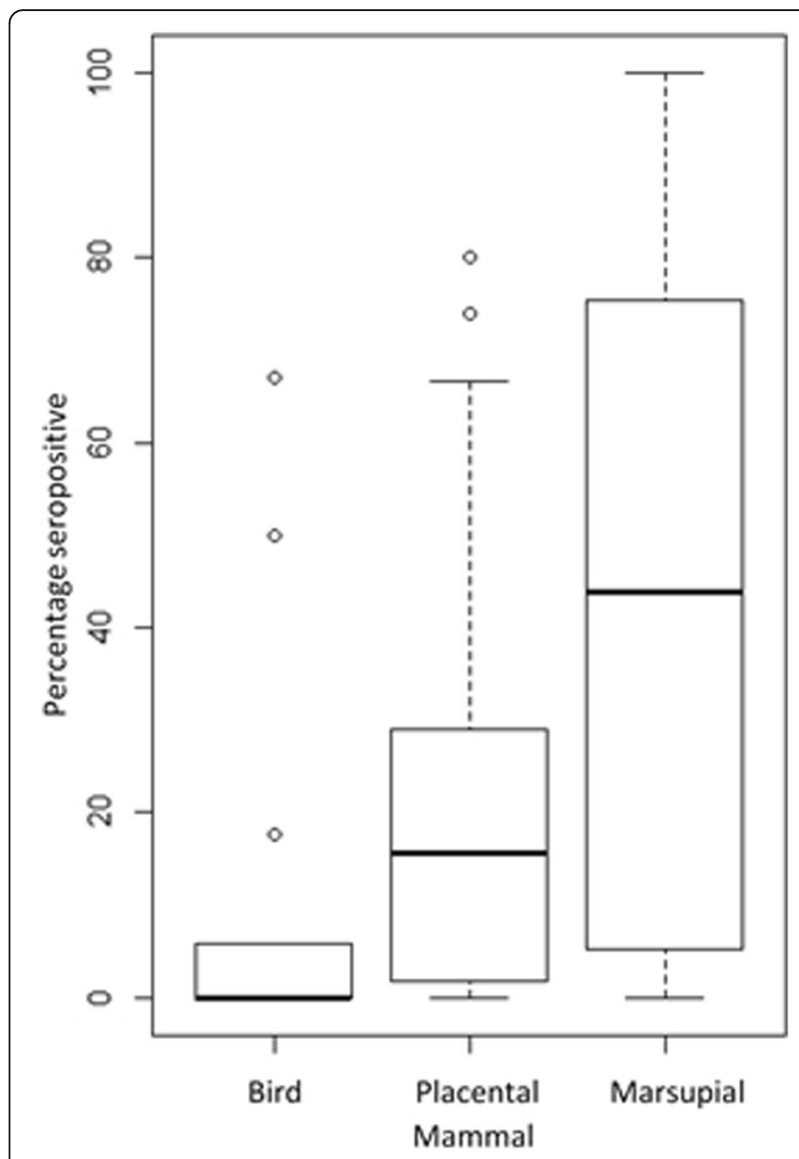

Fig. 3 Boxplot of serosurvey results for each vertebrate group with the number of sera sampled in brackets. Minimum, median and maximum values are represented with the box and whiskers, and outliers are represented by circles

(Oryctolagus cuniculus, 6 of 10 positive). All of the following marsupial species have tested positive to RRV: the eastern barred bandicoot Perameles gunnii $(n=2$ / $2)$, the eastern bettong Bettongia gaimardi $(n=1 / 1)$, the long-nosed potoroo Potorous tridactylus $(n=2 / 2)$, the northern nail-tail wallaby Onychogalea unguifera ( $n$ $=1 / 1)$, the Tasmanian devil Sarcophilus harrisii $(n=4 /$ 4 ) and the tiger quoll Dasyurus maculatus $(n=1 / 1)$.

\section{Discussion}

Identifying reservoirs of multi-host viruses is challenging due to the complex interactions that sustain and promote pathogens and spillover events. For arboviruses, three commonly used criteria for classifying vertebrate reservoirs include: viraemia, virus isolation and relatively high antibody prevalence [3]. In light of these criteria, this study aimed to review the evidence for non-human reservoirs of RRV against the hypothesis: marsupials are better reservoirs of RRV than placental mammals, which are better reservoirs than birds. 


\section{The role of marsupials as reservoirs of RRV}

Results from experimental infection, virus isolation and serosurvey studies on 31 marsupial species support the hypothesis that marsupials are competent reservoirs and likely contribute significantly to RRV transmission. However, the evidence is fragmentary and subject to sampling bias, which limits our ability to extrapolate across species, broad geographical areas, habitat and land use types.

Across experimental infection studies, marsupials generally developed high and long-lasting viraemia. This has previously been interpreted as evidence that marsupials are better reservoirs than other species groups, yet we found no significant difference between the mean duration of viraemia or peak viraemia of marsupials, placental mammals or birds. At least two factors must be considered when interpreting results of experimental infection studies. First, experimental infection studies are often constrained by small sample sizes both in the number of species and the number of studies that can be compared. Although we statistically analysed results from the RRV experimental infection study with the greatest number and diversity of species [27], sample sizes were still limited and likely influenced the statistical power of the results. In particular, the diversity of methods used limits comparisons and the effect of simultaneous co-infection with other viruses cannot be discounted. Secondly, while viraemia plays an important role in the maintenance and transmission of arboviruses, using this measure alone to identify potential reservoirs has limited value. For example, in experimental infection studies of West Nile virus, another zoonotic arbovirus, viraemia alone did not definitively identify vertebrate reservoirs: blue jays (Cyanocitta cristata), house finches (Haemorhous mexicanus) and house sparrows (Passer domesticus) were identified as the most competent reservoirs on the basis of viraemia profile [43]. Yet subsequent field investigations identified that American robins (Turdus migratorius), a less viraemic and relatively uncommon avian species, were responsible for the majority of WNV vector infections due to host feeding preferences [44].

The isolation of virus from naturally infected hosts is interpreted as evidence that the species can infect vector mosquitoes and, thus, infect humans. For marsupials, the isolation of RRV from two free-living agile wallabies (M. agilis) (from a total of 17 tested) demonstrates a vector-host relationship under natural conditions and suggests that this species is capable of infecting susceptible vectors, thereby supporting the argument for the species as reservoirs of RRV. Together with Kay et al.'s [27] observation of viraemia in grey kangaroos, this has led to the hypothesis that macropods are important RRV reservoirs within their range. However, the relative importance of this group of species as a reservoir is not clear, given that RRV has been isolated more frequently from horses and passerine birds and the majority of RRV cases in humans do not overlap with macropod home ranges [13].

Across all studies, marsupials had the highest RRV seroprevalence (44.3\%), compared with placental mammals (22.7\%) and birds (11.1\%). Although informative, these data must be interpreted with caution because it is evident that marsupials were more likely to be targeted during sampling efforts in the decade 1986-1995 (Fig. 2b). This shift in targeted species group followed the results of experimental infection studies demonstrating marsupials as competent amplifiers of RRV in 1986. Further, without information on the age of individuals, seroprevalence data should be compared between studies with caution.

Sampling biases are likely to have arisen from the frequent use of convenience sampling or 'active surveillance' methods (where investigator-driven data collection is designed to meet specific information needs [45]). The focus on marsupials as hosts for RRV to the exclusion of other host species is premature, and is unlikely to be uniform across all marsupial species. For example, brushtail possums were hypothesised to be the urban reservoir of RRV, being both marsupials and living in close proximity to humans [35], resulting in a focus on this species. However, targeted surveillance of this species between February and December 2005 in Sydney failed to identify any seropositive individuals $[35,46]$ of the 10 possums sampled. This number of animals is insufficient to draw strong conclusions about the host status, and further studies are required [46]. Furthermore, it is interesting to note that whilst brushtail possums are an abundant urban marsupial, ringtail possums are more commonly reported in major metropolitan areas including Brisbane, Sydney, Perth, Adelaide and Hobart [47] but only two studies (testing four individuals in total) have been undertaken serological assessments of the species (50\% seropositivity) $[48,49]$.

\section{The role of placental mammals as reservoirs of RRV}

Placental mammals comprise the greatest diversity of species tested, including ungulates, carnivorous and small urban species. While placental mammals meet the three criteria for arboviral reservoirs as a species group, there are significant differences among species.

\section{Ungulates}

Ungulate species, including pigs, horses, sheep and cattle, are recognised as reservoirs for other zoonotic arboviruses [4]. Interestingly for RRV, horses are the only ungulate likely to amplify the disease and act as reservoirs. High, long-lasting viral titres, the ability to infect susceptible mosquitoes, frequent virus isolations and high seroprevalences suggest that horses could contribute significantly to ongoing RRV transmission, particularly during epidemic periods [50], although it is unclear whether they play a role in 
ongoing endemic circulation of RRV. A possible explanation for the high number of RRV isolates from horses is that they are both a domestic species and one of the only known species that develops clinical symptoms to RRV [51] and therefore, are more likely to be sampled, particularly if they were infected and symptomatic. The horse population in Australia may exceed 1.2 million individuals [52], and whilst they are rare in highly urbanised environments, they are abundant in peri-urban areas, where some of the highest prevalence of human RRV infection exists [53].

In contrast, RRV has not been isolated from cattle, pigs and sheep [54-56], and these species have demonstrated low viraemic responses in experimental infection studies [27] and in serosurveys [55]. Large numbers of cattle sera are tested for antibodies to RRV due to the use of cattle as sentinel species in the National Arbovirus Monitoring Program, which is designed to detect incursions of exotic arboviral infection, such as bluetongue viruses [57].

\section{Cats and dogs}

Cats and dogs are the only carnivores that have been assessed as potential reservoir hosts of RRV. Viraemias were not detected following experimental infection and only $10 \%$ of these cats and dogs developed neutralising antibodies to RRV [58]. Seroprevalence studies of domestic cats not experimentally infected, found they have a relatively low antibody prevalence $(12.1 \%)$. The poor amplifier capacity and low seroprevalence suggest these domestic species are unlikely to be significant reservoirs of RRV.

\section{Small mammals $(<2 \mathrm{~kg})$}

The potential role of small placental mammals, such as rodents, rabbits and flying foxes, as reservoir hosts of RRV is ambiguous. Under experimental infection conditions Whitehead [37] found rodents were capable of developing viraemia higher than bandicoots, a marsupial, yet the viraemia was short lived compared to marsupials. Rabbits developed mid-range titre peaks of short duration.

In experimental infection, grey-headed flying foxes (Pteropus poliocephalus) did not develop a detectable viraemia, but were capable of infecting $3 \%$ of recipient Ae. vigilax vectors [33]. Flying foxes are a unique species group because they have been shown to be the reservoir host for several zoonotic pathogens including, henipaviruses lyssaviruses and filoviruses, often without detectable viraemia $[6,59]$. Similar observations have been made for arboviruses. In an experimental infection of black flying foxes (Pt. alecto) with Japanese encephalitis virus, all 15 individuals had a low viraemic response; however, two were capable of infecting susceptible mosquitoes [60]. Only the grey-headed flying fox has been investigated as a potential reservoir host of RRV, yet a blood meal analysis of 20
Ae. funereus vectors in close proximity to a mixed-species flying fox colony in Brisbane found that all of the 16 mosquitoes analysed had fed on black flying foxes and none on grey-headed flying foxes [33]. When considering the possibility of flying foxes as reservoirs of RRV, it is important to consider the height at which different vectors feed and move. Known vectors of RRV, including Ae. vigilax and Ae. camptorhyncus are likely to feed close to the ground, potentially avoiding roosting flying foxes [61]. Further blood meal analysis studies are needed to determine this.

Given their small body size, rats, rodents and flying foxes may be considered less desirable as blood-meals for vectors [62]. However, they may exist in high densities close to human populations. A blood-meal analysis of RRV vectors found rabbits and rats comprised up to $33 \%$ of Cx annulostris blood-meals in urban areas [63]. Serological data supporting the hypothesis that small mammals may be playing a role in the transmission of $R R V$ is currently lacking due to limited numbers tested.

\section{The role of birds as reservoirs of RRV}

Birds are the most common arboviral reservoir for zoonotic flaviviruses and alphaviruses globally [4]; however, their contribution as reservoirs of RRV has been largely overlooked. On the basis of experimental infection viraemia data alone, birds appear to be poor amplifiers of RRV. Four species of birds (chickens, pigeons, little corellas and black ducks) have been experimentally infected with RRV. Across experimental infection studies, birds had the lowest peak titre and the shortest duration of viraemia in comparison to marsupials and placental mammals (Table 3). Furthermore, pigeons were one of the only species that did not develop a detectable viraemia. However, little corellas (Cactua sanguinea) were capable of infecting $14 \%$ of susceptible $C x$ annuilostris mosquitoes, despite having a low and short viraemia. This is important because in the same study, horses developed the highest titre but only infected $11 \%$ of susceptible vectors. Possible reasons for this were not discussed in the original paper, but we suggest the capability of a vertebrate species to infect susceptible mosquito vectors with RRV may be a more relevant measure of reservoir capacity than viraemia.

The isolation of RRV from birds further supports their capacity as amplifiers. More than 750 virus isolation attempts, across 104 species, yielded the first 3 isolates of RRV from the heart muscle of passerine birds in Northern Queensland: a magpie lark, a flycatcher and a masked finch (Table 4). Passerine birds are recognised as important amplifiers of other arboviruses including flaviviruses such as West Nile virus [43], tick-borne pathogens such as Borrelia burgdorferi - the causative agent for Lyme disease [64] and an arthritic alphavirus closely 
related to RRV, Sindbis [65]. Indeed, the isolation of the alphavirus Sindbis from passerine birds, in combination with genetic studies and antibody prevalence investigations has implicated birds as the reservoir host of Sindbis [62].

Serological surveys have found low seroprevalence of RRV in birds. However almost $40 \%$ of bird sera tested has been from sentinel chickens. Chickens are considered appropriate sentinels for flaviviruses such as Murray valley encephalitis because they display a strong antibody response [66], however experimental infections suggest this is not the case for RRV [27, 37]. Notably, birds with positive serology for RRV were free-living native species: a Tawny frogmouth owl in NSW [48] and an Australasian gannet (Morus serrator) sampled in New Zealand [67]. Thus, the tendency towards sampling chickens in RRV serosurveys may underestimate the rates for birds as a whole, and future serosurveys would benefit from inclusion of greater bird species diversity.

\section{Alternative evidence for non-human reservoirs}

This review has focused on the intrinsic host variables important to reservoir capacity. There are other lines of evidence that can be important for investigating potential reservoirs such as blood meal analysis and modelling studies. Determining vector preferences, may indicate a higher feeding frequency, and thus if a capable reservoir, higher transmission rate. Blood meal analysis studies investigate the relationship between the vector and the host. Vector-host choice is a complicated matter, with factors such as host body size, carbon dioxide emission, olfaction, availability, abundance and vector genetics impacting feeding preferences $[62,68]$. Blood meal studies are further complicated as they are easily confounded by the environment in which study took place, and as such these studies are best when accompanied with animal abundance and diversity measures. Of the 12 blood meal analysis papers in Australia, only one [69] has done this by asking the human residents to estimate numbers of animals. Further research is needed to investigate vector-host preferences in Australian urban, peri-urban and rural environments and determine the influence this may have on a species capacity to act as a reservoir.

Mathematical models are valuable way of describing and understanding complex disease systems such as RRV. Models can test assumptions of a disease system and generate predictions which can be used for management decisions. For RRV, five studies [20, 70-73] have utilised mechanistic modelling techniques (e.g. SusceptibleInfectious-Recovered models) to better understand the transmission dynamics underpinning the maintenance of the pathogen. Although the models differ in parameters, location and methods, all include a marsupial reservoir. Species that have been modelled as reservoirs are western grey kangaroos and brushtail possums. Overall these studies found that one host alone was insufficient to maintain virus in vector populations. Glass [72] concluded that although marsupials such as kangaroos and wallabies are generally assumed to be the most important reservoir hosts, the virus survived longed under all models when the marsupial host was replaced with one with a shorter infectious period and higher birth rate. Further, the same study reported that very large host populations (> 100,000 individuals) were required for the virus to survive for four years. Choi et. al. [70] similarly found that a kangaroo reservoir did not impact the number of human infections due to a small population size in the region. Carver et al. [20] reported a significant negative relationship between the abundance of a marsupial reservoir and RRV transmission. These findings are in contrast to the putative reservoir hypothesis. Tompkins \& Slaney [73] noted that different species may be reservoirs in different environments, such as highdensity urban areas and protected environmental habitats, which can result in different transmission cycles. These modelling studies highlight the importance of investigating alternative species as potential reservoirs of RRV. Ideally, the system should be explicitly modelled as a multihost system, but obtaining the necessary data to parameterise such models is challenging [74].

\section{Ross River virus: a multi-host pathogen}

Despite the evidence supporting marsupials as reservoirs of RRV, questions remain. Recent studies have found a high seroprevalence of RRV in the Pacific Islands in the absence of marsupial populations [29, 31], suggesting that marsupials are not the only species group capable of increasing the community infection for RRV. Studies modelling RRV reservoirs have suggested that the pathogen has a multi-host system [23, 72]. However, none of the studies reviewed in this paper specifically examined this hypothesis. Multi-host systems are not uncommon for arboviruses but quantifying these systems is challenging, requiring coordinated data collection over temporal and geographical scales for multiple species [3].

To understand RRV as a multi-host pathogen, two issues must be considered. First, as RRV has an international distribution spanning different environmental and social bounds it is important to define the ecological transmission of RRV across different ecosystems. Expansion of Claflin \& Webb's [14] categorisation of potential RRV vectors, habitats and reservoirs across inland, metropolitan and coastal regions to include transmission cycles is warranted. Secondly, to better understand the reservoir capacity between different host communities, identification of amplifying or diluting reservoir hosts is required. Given that humans are not considered significant maintenance reservoirs of RRV outside of epidemic periods in Australia, this may provide a benchmark for relative comparison of seroprevalence. For example, 
RRV seroprevalence in blood donors shows that the human IgG seroprevalence ranges from 8.38\% in Australia in 2011 [75] to 34.4\% in French Polynesia between 2011 and 2013 [29]. Whilst this only gives an indication of the number of people exposed and does not consider other contributing factors such as duration of antibody response, these data may be compared with animal serosurvey data to identify species with higher infection rates than humans. Vector-host preference may be key to understanding reservoir and transmission dynamics in other zoonotic arboviruses [3]. Overall, consideration of RRV as a multi-host pathogen may disentangle the complex ecological dynamics that may be taking place.

\section{Conclusion}

This study set out to: (i) critically review the evidence for the hypothesis that marsupials are better reservoirs of RRV than mammals, which in turn are better than birds; (ii) identify limitations of this evidence; and (iii) identify research gaps allowing for better assessments of RRV reservoirs in the future. The evidence reviewed in this paper is limited by a sampling bias in favour of particular species and species groups, cross-sectional serosurveys and a diversity of methods employed, which reduces the statistical strength for metaanalysis. Notwithstanding these limitations, this review highlights that evidence to support the stated hypothesis, that marsupials are better reservoirs than placental mammals which in turn are better reservoirs than birds, is variable. Understanding the non-human reservoirs of RRV has broader applications to other zoonotic arboviruses and, importantly, can contribute to the management of current and emerging arboviruses through mitigating infection between host and vector populations. Future research on the non-human reservoirs of RRV should focus on investigating non-marsupial species, including passerine birds and small placental mammals. Ideally this would be done through ecological assessments of vector, virus and host abundance in areas of high and low disease in humans. For Australia, reducing the burden of RRV, the most common arbovirus, would have substantial economic and social benefits.

\section{Additional files}

Additional file 1: Table S1. Combinations of search terms used to collect papers for review. Table S2. Detailed summary of included Ross River virus reservoir studies, including the reference, location, study type and species group assessed in each study. (DOCX $22 \mathrm{~kb}$ )

Additional file 2: Figure S1. Flowchart outlining the process followed and actions taken to compile the systematic literature review. The box in yellow highlights the total number of studies used in this review. The total number $n$ is the number of original research papers. (PNG $29 \mathrm{~kb}$ )

\section{Abbreviations}

ANOVA: Analysis of Variance; ELISA: Enzyme linked immunosorbent assay; PRNT: Plaque reduction neutralisation; RRV: Ross River virus

\section{Acknowledgments}

We would like to acknowledge Wildlife Health Australia for their assistance with gathering sources for this review.

\section{Funding}

ES was supported by Australian Government Research Training Program Scholarship. AJP was supported by a Queensland Government Accelerate Postdoctoral Research Fellowship.

\section{Availability of data and materials}

The datasets used and/or analysed during the current study are available from the corresponding author on reasonable request.

\section{Authors' contributions}

ES collected, analysed, interpreted papers and was a major contributor in the writing of the manuscript. AP, SR, CC and HM contributed to the interpretation of results and writing of the manuscript. All authors read and approved the final manuscript.

Ethics approval and consent to participate

Not applicable.

Consent for publication

Not applicable.

Competing interests

The authors declare that they have no competing interests.

\section{Publisher's Note}

Springer Nature remains neutral with regard to jurisdictional claims in published maps and institutional affiliations.

\section{Author details}

${ }^{1}$ Environmental Futures Research Institute, Griffith University, Brisbane, Queensland 4111, Australia. ${ }^{2}$ The University of Queensland, School of Public Health, Herston, Brisbane, Queensland 4006, Australia. ${ }^{3}$ Metro North Public Health Unit, Metro North Hospital and Health Service, Windsor, Brisbane, Queensland 4030, Australia. ${ }^{4}$ Communicable Diseases Branch, Department of Health, Queensland Government, Herston, Brisbane, Queensland 4006, Australia.

Received: 18 October 2017 Accepted: 20 February 2018

Published online: 19 March 2018

\section{References}

1. Karesh WB, Dobson A, Lloyd-Smith JO, Lubroth J, Dixon MA, Bennett M, et al. Ecology of zoonoses: natural and unnatural histories. Lancet. 2012;380(9857):1936-45.

2. Webster JP, Borlase A, Rudge JW. Who acquires infection from whom and how? Disentangling multi-host and multi-mode transmission dynamics in the 'elimination'era. Phil Trans R Soc B. 2017;372(1719):20160019.

3. Kuno G, Chang GJ. Biological transmission of arboviruses: reexamination of and new insights into components, mechanisms, and unique traits as well as their evolutionary trends. Clin Microbiol Rev. 2005;18(4):608-37.

4. Weaver SC, Barrett AD. Transmission cycles, host range, evolution and emergence of arboviral disease. Nat Rev Microbiol. 2004;2(10):789-801.

5. Plowright RK, Parrish CR, McCallum H, Hudson PJ, Ko Al, Graham AL, et al. Pathways to zoonotic spillover. Nat Rev Microbiol. 2017:15:502-10.

6. Plowright RK, Peel AJ, Streicker DG, Gilbert AT, McCallum H, Wood J, et al. Transmission or within-host dynamics driving pulses of zoonotic viruses in reservoir-host populations. PLoS Negl Trop Dis. 2016;10(8):e0004796.

7. Haydon DT, Cleaveland S, Taylor LH, Laurenson MK. Identifying reservoirs of infection: a conceptual and practical challenge. Emerg Infect Dis. 2002;8(12):1468-73.

8. Viana M, Mancy R, Biek R, Cleaveland S, Cross PC, Lloyd-Smith JO, et al. Assembling evidence for identifying reservoirs of infection. Trends Ecol Evol. 2014:29(5):270-9.

9. Kuno G, Mackenzie JS, Junglen S, Hubálek Z, Plyusnin A, Gubler DJ. Vertebrate reservoirs of arboviruses: Myth, synonym of amplifier, or reality? Viruses. 2017;9(7):185. 
10. World Health Organization. Arthropod-borne and rodent-borne viral diseases: report of a WHO scientific group meeting held in Geneva from 28 February to 4 March 1983. 1985. http://apps.who.int/iris/handle/10665/39922. Accessed 31 Aug 2017.

11. Rodhain F. The idea of natural reservoir in arbovirology. Bull Soci Pathol Exot. 1997:91(4):279-82.

12. National Notifiable Diseases Surveillance System. Australian Government, Department of Health. 2017. http://www9.health.gov.au/cda/source/cdaindex.cfm. Accessed 12 Sep 2017.

13. Harley D, Sleigh A, Ritchie S. Ross River virus transmission, infection, and disease: a cross-disciplinary review. Clin Microbio Rev. 2001;14(4):909-32.

14. Claflin SB, Webb CE. Ross River virus: many vectors and unusual hosts make for an unpredictable pathogen. PLoS Pathogens. 2015;11(9):e1005070.

15. Condon RJ, Rouse IL. Acute symptoms and sequelae of Ross River virus infection in South Western Australia. A follow up study. Clin Diag Virol. 1995:3(3):273-84

16. Schleenvoigt BT, Baier M, Hagel S, Forstner C, Koetsche R, Pletz MW. Ross river virus infection in a Thuringian traveller returning from south-east Australia. Infection. 2015:43(2):229-30.

17. Ratnayake JTB. The valuation of social and economic costs of mosquitotransmitted Ross River virus: PhD Thesis. Brisbane: Griffith University; 2006.

18. Tomerini DM, Dale PE, Sipe N. Does mosquito control have an effect on mosquito-borne disease? The case of Ross River virus disease and mosquito management in Queensland, Australia. J Am Mosq Cont Assoc. 2011;27(1):39-44.

19. Russell RC. Ross River virus: Ecology and distribution. Annu Rev Entomol. 2002;47:1-31.

20. Carver S, Bestall A, Jardine A, Ostfeld RS. Influence of hosts on the ecology of arboviral transmission: potential mechanisms influencing dengue, Murray Valley encephalitis, and Ross River virus in Australia. Vector Borne Zoonotic Dis. 2009;9(1):51-64.

21. Jacups SP, Whelan PI, Currie BJ. Ross River virus and Barmah Forest virus infections: A review of history, ecology, and predictive models, with implications for tropical northern Australia. Vector Borne Zoonotic Dis. 2008;8(2):283-97.

22. $\mathrm{Ng} \mathrm{V}$, Dear K, Harley D, McMichael A. Analysis and prediction of Ross River virus transmission in New South Wales, Australia. Vector Borne Zoonotic Dis. 2014;14(6):422-38

23. Koolhof I, Carver S. Epidemic host community contribution to mosquito-borne disease transmission: Ross River virus. Epidemiol Infect. 2017;145(4):656-66

24. Marshall I, Miles J. Ross River virus and epidemic polyarthritis. Curr Top Vector Res. 1984;2:31-56.

25. Rosen L, Gubler DJ, Bennett PH. Epidemic polyarthritis (Ross River) virus infection in the Cook Islands. Am J Trop Med Hyg. 1981;30(6):1294-302.

26. Jacups SP, Whelan PI, Markey PG, Cleland SJ, Williamson GJ, Currie BJ. Predictive indicators for Ross River virus infection in the Darwin area of tropical northern Australia, using long-term mosquito trapping data. Trop Med Int Health. 2008;13(7):943-52.

27. Kay BH, Hall RA, Fanning ID, Mottram P, Young PL, Pollitt CC. Experimental infection of vertebrates with Murray Valley encephalitis and Ross River viruses. In: Arboviral Research of Australia: Proceedings Fourth Symposium May 6-9, 1986. Brisbane; 1986. p. 71-5.

28. Doherty RL, Standfast HA, Domrow R, Wetters EJ, Whitehead RH, Carley JG. Epidemiology of arthropod-borne virus infections at Mitchell River Mission, Cape York Peninsula, North Queensland. IV. Arbovirus infections of mosquitoes and mammals, 1967-1969. Trans R Soc Trop Med Hyg. 1971; 65(4):504.

29. Aubry M, Finke J, Teissier A, Roche C, Broult J, Paulous S, et al. Silent circulation of Ross River virus in French Polynesia. Int J Infect Dis. 2015;37:19-24.

30. Aubry M, Finke J, Teissier A, Roche C, Broult J, Paulous S, et al. Seroprevalence of arboviruses among blood donors in French Polynesia, 2011-2013. Int J Infect Dis. 2015:41:11-2

31. Lau C, Aubry M, Musso D, Teissier A, Paulous S, Desprès $P$, et al. New evidence for endemic circulation of Ross River virus in the Pacific Islands and the potential for emergence. Int J Infect Dis. 2017;57:73-6.

32. Studdert MJ, Azoulas JK, Vasey JR, Hall RA, Ficorilli N, Huang JA. Polymerase chain reaction tests for the identification of Ross River, Kunjin and Murray Valley encephalitis virus infections in horses. Aust Vet J. 2003;8(1):76-80

33. Ryan PA, Martin L, Mackenzie JS, Kay BH. Investigation of gray-headed flying foxes Pteropus poliocephalus (Megachiroptera: Pteropodidae) and mosquitoes in the ecology of Ross River virus in Australia. Am J Trop Med Hyg. 1997;57(4):476-82.
34. Kay BH, Pollitt CC, Fanning ID, Hall RA. The experimental infection of horses with Murray Valley encephalitis and Ross River viruses. Aust Vet J. 1987;64(2):52-5

35. Boyd AM, Hall RA, Gemmell RT, Kay BH. Experimental infection of Australian brushtail possums, Trichosurus vulpecula (Phalangeridae : Marsupialia), with Ross River and Barmah Forest viruses by use of a natural mosquito vector system. Am J Trop Med Hyg. 2001;65(6):777-82.

36. Kay BH, Standfast HA. Ecology of arboviruses and their vectors in Australia. Curr Top Vect Res. 1987:3:1-36.

37. Whitehead R. Experimental infection of vertebrates with Ross River and Sindbis viruses 2 Group A arboviruses isolated in Australia. Aust J Exp Biol Med Sci. 1969;47:11.

38. Whitehead R, Doherty R, Domrow R, Standfast H, Wetters E. Studies of the epidemiology of arthropod-borne virus infections at Mitchell River Mission, Cape York Peninsula, North Queensland: III. Virus studies of wild birds, 1964 1967. Trans R Soc Trop Med Hyg. 1968;62(3):439-45.

39. Pascoe R, George T, Cybinski D. The isolation of a Ross River virus from a horse. Aust Vet J. 1978;54(12):600

40. Azuolas JK, Wishart E, Bibby S, Ainsworth C. Isolation of Ross River virus from mosquitoes and from horses with signs of musculo-skeletal disease. Aust Vet J. 2003:81(6):344-7.

41. Hobson-Peters J. Approaches for the development of rapid serological assays for surveillance and diagnosis of infections caused by zoonotic flaviviruses of the Japanese encephalitis virus serocomplex. BioMed Res Int. 2012;2012:379738.

42. Potter A, Johansen CA, Fenwick S, Reid SA, Lindsay M. The seroprevalence and factors associated with Ross River virus infection in western grey kangaroos Macropus fuliginosus in Western Australia. Vector Borne Zoonotic Dis. 2014:14(10):740-5.

43. Komar N, Langevin S, Hinten S, Nemeth N, Edwards E, Hettler D, et al. Experimental infection of North American birds with the New York 1999 strain of West Nile virus. Emerg Infect Dis. 2003;9(3):311.

44. Kilpatrick AM, Daszak P, Jones MJ, Marra PP, Kramer LD. Host heterogeneity dominates West Nile virus transmission. Proc R Soc Lond B Biol Sci. 2006:273(1599):2327-33.

45. Stallknecht D. Impediments to wildlife disease surveillance, research, and diagnostics. In: Childs JE, Mackenzie JS, Richt JA, editors. Wildlife and emerging zoonotic diseases: The biology, circumstances and consequences of cross-species transmission. Berlin: Springer; 2007. p. 445-61.

46. Hill NJ, Power ML, Deane EM. Absence of Ross River virus amongst Common brushtail possums Trichosurus vulpecula from metropolitan Sydney, Australia. Eur J Wildl Res. 2009;55(3):313-6.

47. Atlas of Living Australia. 2017. http://www.ala.org.au. Accessed 15 Dec 2017.

48. Gard G, Marshall ID, Woodroof GM. Annually recurrent epidemic polyarthritis and Ross River virus activity in a coastal area of New South Wales. II. Mosquitos, viruses and wildlife. Am J Trop Med Hyg. 1973;22(4):551-60.

49. McManus TJ, Marshall ID. The epidemiology of Ross River virus in Tasmania. Arbov Res Aust. 1986:127-31.

50. Roche SE, Wicks R, Garner MG, East IJ, Paskin R, Moloney BJ, et al. Descriptive overview of the 2011 epidemic of arboviral disease in horses in Australia. Aust Vet J. 2013;91(1):5-13.

51. Azuolas JK. Ross River virus disease of horses. Aust Equin Vet. 1998:16(2):56-8.

52. McGowan TW, Pinchbeck G, Phillips CJC, Perkins N, Hodgson DR, McGowan CM. A survey of aged horses in Queensland, Australia. Part 1: Management and preventive health care. Aust Vet J. 2010;8811:420-7.

53. Hu W, Tong S, Mengersen K, Oldenburg B. Exploratory spatial analysis of social and environmental factors associated with the incidence of Ross River virus in Brisbane. Australia. Am J Trop Med Hyg. 2007;76(5):814-9.

54. Gard G, Shorthose J, Weir R, Walsh S, Melville L. Arboviruses recovered from sentinel livestock in northern Australia. Vet Microbio. 1988;18(2):109-18.

55. Spradbrow PB. Experimenatl infection of sheep and pigs with Ross Rive virus. Aust Vet J. 1973;49(8):403-4

56. Vale TG, Spratt DM, Cloonan MJ. Serological evidence of arbovirus infection in native and domesticated mammals on the south coast of New South Wales, Australia. Aust J Zoolo. 1991:39(1):1-8.

57. Gard G, Weir R, Walsh S. Arboviruses recovered from sentinel cattle using several virus isolation methods. Vet Microbio. 1988;18(2):119-25.

58. Boyd AM, Kay BH. Assessment of the potential of dogs and cats as urban reservoirs of Ross River and Barmah Forest viruses. Aust Vet J. 2002;80(1):83-6.

59. Brook CE, Dobson AP. Bats as 'special'reservoirs for emerging zoonotic pathogens. Trends Microbio. 2015;23(3):172-80. 
60. Van den Hurk AF, Smith CS, Field HE, Smith IL, Northill JA, Taylor CT, et al. Transmission of Japanese encephalitis virus from the black flying fox, Pteropus alecto, to Culex annulirostris mosquitoes, despite the absence of detectable viremia. Am J Trop Med Hyg. 2009;81(3):457-62.

61. Johnston E, Weinstein P, Slaney D, Flies AS, Fricker S, Williams C. Mosquito communities with trap height and urban-rural gradient in Adelaide, South Australia: implications for disease vector surveillance. J Vect Ecol. 2014;39(1):48-55.

62. Lyimo IN, Ferguson HM. Ecological and evolutionary determinants of host species choice in mosquito vectors. Trends Parasitol. 2009;25(4):189-96.

63. Jansen CC, Webb CE, Graham GC, Craig SB, Zborowski P, Ritchie SA, et al. Blood sources of mosquitoes collected from urban and peri-urban environments in eastern Australia with species-specific molecular analysis of avian blood meals. Am J Trop Med Hyg. 2009;81(5):849-57.

64. Comstedt P, Bergstrom S, Olsen B, Garpmo U, Marjavaara L, Mejlon H, et al. Migratory passerine birds as reservoirs of Lyme borreliosis in Europe. Emerg Infect Dis. 2006;12(7):1087-95.

65. Lundström JO, Lindström KM, Olsen B, Dufva R, Krakower DS. Prevalence of Sindbis virus neutralizing antibodies among Swedish passerines indicates that thrushes are the main amplifying hosts. J Med Entomol. 2001;38(2):289-97.

66. Chung YS, Spradbrow PB. Survey for antibodies to arboviruses in domesticfowls in Queensland. Aust Vet J. 1973;49(12):564.

67. Tompkins D, Johansen C, Jakob-Hoff R, Pulford D, Castro I, Mackereth G. Surveillance for arboviral zoonoses in New Zealand birds. West Pac Surveill Resp J. 2013;4(4):16-23.

68. Takken W, Verhulst NO. Host preferences of blood-feeding mosquitoes. Annu Rev Entomol. 2013;58:433-53.

69. Kay BH, Boyd AM, Ryan PA, Hall RA. Mosquito feeding patterns and natural infection of vertebrates with Ross River and Barmah Forest viruses in Brisbane, Australia. Am J Trop Med Hyg. 2007;76(3):417-23.

70. Choi YH, Comiskey C, Lindsay MDA, Cross JA, Anderson M. Modelling the transmission dynamics of Ross River virus in southwestern Australia. Ima J Math Appl Med Biol. 2002;19(1):61-74.

71. Denholm L, Beeton NJ, Forbes LK, Carver S. A model for the dynamics of Ross River Virus in the Australian environment. Letters Biomath. 2017;4(1):187-206.

72. Glass K. Ecological mechanisms that promote arbovirus sunvival: a mathematical model of Ross River virus transmission. Trans R Soc Trop Med Hyg. 2005;99(4):252-60.

73. Tompkins DM, Slaney D. Exploring the potential for Ross River virus emergence in New Zealand. Vector Borne Zoonotic Dis. 2014;14(2):141-8.

74. Buhnerkempe MG, Roberts MP, Dobson AP, Heesterbeek H, Hudson PJ, Lloyd-Smith JO. Eight challenges in modelling disease ecology in multi-host, multi-agent systems. Epidemics. 2015;10:26-30.

75. Faddy H, Dunford M, Seed C, Olds A, Harley D, Dean M, et al. Seroprevalence of antibodies to Ross River and Barmah Forest viruses: Possible implications for blood transfusion safety after extreme weather events. EcoHealth. 2015;12(2):347-53.

76. Campbell J, Aldred J, Davis G. Some aspects of the natural history of Ross River virus in south-east Gippsland, Victoria. In: Arbovirus research in Australia Proceedings Fifth Symposium, August 28-September 1, 1989. Brisbane; 1989. p. 24-8.

\section{Submit your next manuscript to BioMed Central and we will help you at every step:}

- We accept pre-submission inquiries

- Our selector tool helps you to find the most relevant journal

- We provide round the clock customer support

- Convenient online submission

- Thorough peer review

- Inclusion in PubMed and all major indexing services

- Maximum visibility for your research

Submit your manuscript at www.biomedcentral.com/submit 